\title{
Application of General Tool-life Function under Changing Cutting Conditions
}

\author{
János Kundrák, Zoltán Pálmai \\ Department of Production Engineering, University of Miskolc \\ Egyetemváros, H-3515 Miskolc, Hungary \\ janos.kundrak@uni-miskolc.hu; gepgyartas@uni-miskolc.hu
}

\begin{abstract}
The traditional Taylor formula $T=f\left(v_{c}\right)$ gives tool life of the cutting tool $T$ as a function of the cutting speed at constant speeds in which the higher the speed, the lower the tool life. However, in a wider technological range, the function $T=f\left(v_{c}\right)$ has extreme values as well, which can be described by the general tool-life function. Frequently the tool is used until full wear of the edge at changing or alternating speeds, for which the general tool-life function can be extended. By using this extension, the general tool-life equation can be defined even under manufacturing conditions. Its applicability is demonstrated for examples of taper-turning and cutting optimisation.
\end{abstract}

Keywords: hard turning; tool life; economical cutting

\section{Introduction}

Several characteristics of machining are known, such as the surface quality of the workpiece, the shape of the chip, etc., and undoubtedly a great deal of attention is paid to tool life. Most often it is calculated by the well-known Taylor formula [1]

$v_{c} \cdot T^{-\frac{1}{k}}=C_{v}$

where $v_{c}$ is cutting speed and $T$ is tool life, while $-k$ and $C_{v}$ are constants that are functions of the cutting conditions. Such conditions include the characteristics of the workpiece and the tool, the tool geometry and the cutting parameters (feed, depth of cut). On the basis of the Taylor formula several new research results have been obtained, such as the study by El Baradie [2] examining how the workpiece diameter influences the tool edge, or the examinations by Arsecuralante et al., who measured the volume of the material removed till the wear off of the tool edge [3], and who explained the tool wear by thematically activated processes [4]. Sahin [5], through a multiple regression analysis, attempted to apply a quadratic model that takes the hardness of the tool into account and also handles the product of the hardness and cutting speed, as well as the hardness and feed as separate 
technological variables. The cutting forces and chip morphology also were taken into account when examining coated tool materials as, for example, Chinchanikar and Choudhunry [6] did in their experimental study. Still, similarly to other cutting investigations, the common characteristic feature of these differently orientated studies applying different methods is that they summarise the results in Taylor-like formulas.

The tool life equation is just as important from the point of view of the theory and practice of cutting. When qualifying the surfaces of the workpieces, which is often complicated [7], the state of the tool also has to be defined accurately, in addition to the cutting parameters. In the case of complicated procedures like the $3 \mathrm{D}$ end ball milling of steels [8], the knowledge of tool wear is needed for the actual realisation of the theoretically expected surface roughness. In turning alloys which are difficult to machine, such as Inconel, the planning of tool wear is especially important [9], and when optimising the cutting technology it is essential [10].

However, there are two obstacles (limitations) to the general application of the Taylor formula. The first one is that $\mathrm{v}_{\mathrm{c}}-\mathrm{T}$ tool-life function is general, having extreme values but over a wide range of technological parameters rather than monotonously decreasing values, as is presented in Figure 1. The second obstacle is that the tool is used with alternating or changing cutting speed. A cutting test must be done where the cutting speed changes, both in the planning of practical technology and in the validation of the SEM simulation of tool wear [11]. In a case such as this not only the definition of tool life is questionable, but even its interpretation. Bridging these difficulties is the aim of this paper.

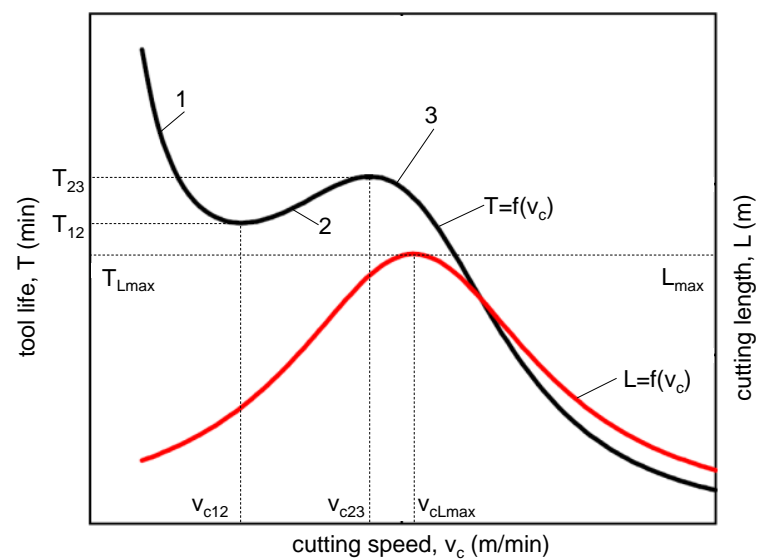

Figure 1

General tool-life function and the through cut length 


\section{General Tool-Life Function}

Kundrák has demonstrated before that the general tool-life function worked out by him [12], which can be seen in Figure 1, describes the whole $v_{c}-T$ function. Later other similar attempts became known [13] which rely on a rather complicated mathematical model, thus their practical application is laborious. The Kundrák formula that takes cutting speed into account can be written as:

$T=\frac{C_{T 1}}{v_{c}^{3}+C_{T 2} \cdot v_{c}^{2}+C_{T 3} \cdot v_{c}}$

where $C_{T 1}, C_{T 2}$ and $C_{T 3}$ are constants. At speeds $v_{c 12}$ and $v_{c 23}$ this function has an extreme value, which is naturally influenced by the technological parameters (feed $f$ and depth of cut $a_{p}$ ):

$v_{c 12}=C_{v_{c 12}} \cdot f^{x_{12}} \cdot a_{p}^{y_{12}} \cdot d_{w}^{q_{12}}$

$v_{c 23}=C_{v_{c 23}} \cdot f^{x_{23}} \cdot a_{p}^{y_{23}} \cdot d_{w}^{q_{23}}$

$T_{23}=C_{T 23} \cdot f^{x_{T_{23}}} \cdot a_{p}^{y_{T_{23}}}$

where $d_{w}$ is the diameter of the workpiece, $C_{v_{c 12}}, C_{v_{c 23}}, C_{T 23}$ and $x_{12}, y_{12}, q_{12}, x_{23}$, $y_{23}, q_{23}, x_{T 23}, y_{T_{23}}$ are constants that can be defined by technological examinations [12].

By their use already the constants of the general tool-life equation (1) can be calculated:

$C_{T 1}=T_{23} \cdot\left(v_{c 23}^{3}+C_{T 2} \cdot v_{c 23}^{2}+C_{T 3} \cdot v_{c 23}\right)$

$C_{T 2}=-\frac{3}{2} \cdot\left(v_{c 12}+v_{c 23}\right)$

$C_{T 3}=3 \cdot v_{c 12} \cdot v_{c 23}$

It frequently occurs in technological planning practice that the length cut through the wear of the edge has to be examined or used, which, using (2), can be calculated by the formula:

$L=T \cdot v_{c}=\frac{C_{T 1}}{v_{c}^{2}+C_{T 2} \cdot v_{c}+C_{T 3}}$

This $\mathrm{L}\left(\mathrm{v}_{\mathrm{c}}\right)$ function has only one extreme value (maximum) at speed

$v_{L \max }=-\frac{C_{T 2}}{2}$ 
and its value can be calculated by

$$
L_{\max }=\frac{C_{T 1}}{0.75 \cdot C_{T 2}^{2}+C_{T 3}}
$$

The tool-life function and cutting length defined in this way can be used in a wide range of technological parameters $[14,15]$ and thus one of the problems mentioned in the Introduction in connection with the Taylor formula can be eliminated. Later we provide a solution for the frequently occurring cases of cutting alternating in stages or changing continuously. Henceforth, tool life at fixed (unchanging) speeds is indicated with $\mathrm{T}_{\mathrm{vc}, \text { fix }}$, while it is indicated with $\mathrm{T}_{\mathrm{vc} \text {, vari }}$ at variable (changing) speeds.

\section{Tool Life when Changing Cutting Speed}

The solution is based on the principle of the proportional degradation of the tool. If speeds change in stages, which is the case presented in Figure 2, as cutting is done at different speeds the wear of the tool is naturally cumulative [16].

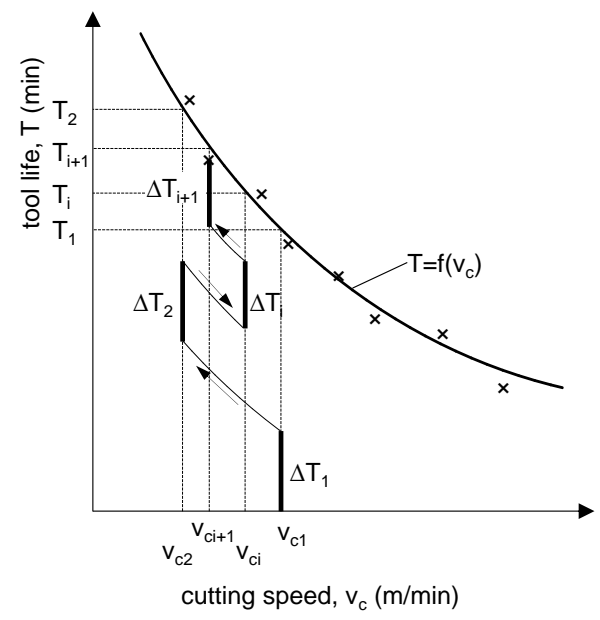

Figure 2

Tool life at changing cutting speed

It is a proved fact that if cutting is done for $\Delta t_{i}$ time at cutting speed $v_{c i}$, the corresponding tool life is $T_{i}$, and the following equation is valid [16]:

$\sum_{i=1}^{N} \frac{\Delta t_{i}\left(v_{c i}\right)}{T_{i}\left(v_{c i}\right)} \cong 1$

where $\mathrm{N}$ is the number of the cutting stages [16]. 
Although it can easily be proved that by means of the Zorev power function

$$
V B=C_{V B} \cdot t^{u}
$$

$(\mathrm{u}=0.5-1)$ [17] the sum of Equation (12) can be described exactly as 1 in wear functions, this is valid only until inflection is reached on the wear curve. In wear curves in which there is inflection, too, Equation (12) can be considered as an approximation before reaching the wear defined as tool-life criterion. As is known, the degradation of the tool is the consequence of the accumulated influence of several processes, where occasionally a sudden disorder occurs such as chipping away or pitting [18]. Such cases are not covered by this investigation. If cutting speed changes continuously, as in cross turning or taper turning, the equation takes the form

$$
\int_{t_{1}}^{t_{2}} \frac{d t}{T\left(v_{c}\right)} \cong 1
$$

where $\mathrm{v}_{\mathrm{c}}=\mathrm{v}_{\mathrm{c}}(\mathrm{t})$ is a function of time [19]. By connecting Equations (2), (12) and (14), a general tool-life equation can be gained which is valid for a wide range of cutting speeds, in the case of both constant and changing cutting speed. For cutting speed changing in stages

$\sum_{i=1}^{N} \Delta t_{i} \cdot\left(v_{c i}^{3}+C_{T 2} \cdot v_{c i}^{2}+C_{T 3} \cdot v_{c i}\right) \cong C_{T 1}$

however, for continuously changing cutting speed (e.g. taper turning or cross turning)

$$
\int_{\mathrm{t}_{1}}^{\mathrm{t}_{2}}\left[\mathrm{v}_{\mathrm{c}}^{3}(\mathrm{t})+\mathrm{C}_{\mathrm{T} 2} \cdot \mathrm{v}_{\mathrm{c}}^{2}(\mathrm{t})+\mathrm{C}_{\mathrm{T} 3} \cdot \mathrm{v}_{\mathrm{c}}(\mathrm{t})\right] \mathrm{dt} \cong \mathrm{C}_{\mathrm{T} 1}
$$

Using these equations and the general tool-life equation (12) valid for the cutting speed changing in stages,

$$
T=\frac{\sum_{1}^{N} \Delta t_{i}\left(v_{c i}^{3}+C_{T 2} \cdot v_{c i}^{2}+C_{T 3} \cdot v_{c i}\right)}{v_{c}^{3}+C_{T 2} \cdot v_{c}^{2}+C_{T 3} \cdot v_{c}}
$$

and using Equation (14) at continuously changing cutting speed

$$
T=\frac{\int_{t_{1}}^{t_{2}}\left[v_{c}^{3}(t)+C_{T 2} \cdot v_{c}^{2}(t)+C_{T 3} \cdot v_{c}(t)\right] d t}{v_{c}^{3}+C_{T 2} \cdot v_{c}^{2}+C_{T 3} \cdot v_{c}}
$$

Equations (17) and (18), once we know constants $C_{T 2}$ and $C_{T 3}$, can be handled numerically. 
These functions are valid if all conditions with the exception of cutting speed $v_{c}$ remain unchanged throughout the tool life. $T$ calculated in this way cannot be considered as tool life in the strict sense, since tool life, according to the definition, means the time of cutting during which at a given $v_{c}$ cutting speed a predetermined amount of wear - the tool-life criterion - develops on the tool. However, here the cutting speed is not unchanged till the edge wears off, rather it changes either periodically or continuously. The usual $\mathrm{v}_{\mathrm{c}}-\mathrm{T}$ data pair may occur if, besides the cutting time calculated by Equations (17) or (18), using Equation (2) $v_{c, e q}$ is also calculated which is considered constant, and $\mathrm{T}=\mathrm{T}_{\text {eq }}$ can really be considered as tool life. This has significance in the economic or technological optimisation of productivity.

Essentially there are two basic cases of the practical utilisation of Equations (17) and (18) in the tool-life function (1):

a) $\quad C_{T i}$ constants of Equations (17) and (18) are known and identical tools are used in operations carried out at either periodically or continuously changing speeds. Now, to define the number of workpieces that can be produced before the tool wears off $N_{p}$, using the data of the operation plan and also Equations $(12,14)$,

$$
N_{p}=\frac{C_{T 1}}{\sum_{1}^{N} \Delta t_{i} \cdot\left(v_{c i}^{3}+C_{T 2} \cdot v_{c i}^{2}+C_{T 3} \cdot v_{c i}\right)}
$$

and

$$
N_{p}=\frac{\int_{0}^{t_{p}}\left[v_{c}^{3}(t)+C_{T 2} \cdot v_{c}^{2}(t)+C_{T 3} \cdot v_{c}(t)\right] d t}{k \cdot\left(v_{c}^{2}+C_{T 2} \cdot v_{c}+C_{T 3}\right)}
$$

can be applied, where

$$
k=\frac{t_{p}}{v_{c}}=\frac{L_{p} \cdot D_{w} \cdot \pi}{1000 \cdot v_{c} \cdot f},
$$

where $D_{w}(\mathrm{~mm})$ is the diameter of the workpiece, $f(\mathrm{~mm} / \mathrm{rev})$ is feed, $L_{p}(\mathrm{~mm})$ is the length that can be cut by the piece, $t_{p}$ is the operation time. These parameters can be used for data collection during production as well if the approach is reversed: the number of the different machined parts is registered for the tool used until it is worn off. The results can be used for the refinement of Equations (15) and (16) that is the $C_{T i}$ constants, as well.

b) $\quad C_{T i}$ constants of the equation are not known. Then data $N_{p, i}$ can be collected for the values of $\Delta t_{i}$ and $v_{c i}$. There will be $N_{p, i}$ data, too, for all the worn out tools, for which Equations (12) and (14) are true. Many equations (15), (16) offer themselves for the unknown $C_{T 1}$ and other constants as the worn off edges; that is, a linear equation system with a minimum of three equations will be dealt with, from which these constants can be calculated. 


\section{Cutting Model Experiment}

Hard turning was completed by cutting an $\varnothing 45 \mathrm{~mm}$ inner cylindrical surface of $100 \mathrm{Cr} 6$ hardened steel $(\mathrm{HRC}=62 \pm 2)$ on an E400-1000 centre lathe. The length of the machined bore hole was $\mathrm{L}_{\mathrm{p}}=30 \mathrm{~mm}$. The characteristics of the tool: CBN K10, $\gamma=-5^{\circ}, \alpha=\alpha^{\prime}=15^{\circ}, \lambda=0^{\circ}, \kappa_{\mathrm{r}}=45^{\circ}, \kappa_{\mathrm{r}}{ }^{\prime}=15^{\circ}$, the applied feed $f=0.075 \mathrm{~mm} / \mathrm{rev}$., depth of cut $\mathrm{a}_{\mathrm{p}}=0.1 \mathrm{~mm}$. The constants of the tool-life formula given in Equation (2) related to the boring of this material are summed up in Table 1, and the $\mathrm{v}_{\mathrm{c}}-\mathrm{T}_{\mathrm{vc} \text {,fix }}$ tool life curve defined this way for cutting by fixed speed can be seen in Figure 3.

For the comparison of cutting at a fixed and at periodically changing speed, Table 2 , for 5 chosen revolution values, displays the $N_{p, i}$ number of workpieces completed before a tool wears out; that is, tool life is indicated by the number of the turned bore holes. Table 3 summarises the model experiment series in which the number of pieces $N_{p, i}$ is measured that can be produced by turning at two speeds each, chosen from the 5 different speeds. Index I refers to the cutting speeds listed in Table 2, and $\Delta \mathrm{t}_{\mathrm{i}}=\mathrm{N}_{\mathrm{p}, \mathrm{i}} \times \mathrm{t}_{\mathrm{p} \mathrm{i}}$. These $T_{\text {meas }}$ tool lives can also be seen in Figure 3.

Table 1

Constants of functions in Equations (3)-(5) with K10 tool [2]

\begin{tabular}{|c|c|c|c|}
\hline $\mathrm{C}_{\mathrm{v}_{\mathrm{c} 12}}$ & $\mathrm{x}_{\mathrm{v}_{12}}$ & $\mathrm{y}_{\mathrm{v}_{12}}$ & $\mathrm{q}_{\mathrm{v}_{12}}$ \\
\hline 1.06 & -0.41 & -0.40 & 0.19 \\
\hline $\mathrm{C}_{\mathrm{v}_{\mathrm{c} 23}}$ & $\mathrm{x}_{\mathrm{v}_{23}}$ & $\mathrm{y}_{\mathrm{v}_{23}}$ & $\mathrm{q}_{\mathrm{v}_{23}}$ \\
\hline 3.32 & -0.24 & -0.49 & 0.16 \\
\hline $\mathrm{C}_{\mathrm{T} 23}$ & $\mathrm{x}_{\mathrm{T}_{23}}$ & $\mathrm{y}_{\mathrm{T}_{23}}$ & $\mathrm{q}_{\mathrm{T}_{23}}$ \\
\hline 13.99 & -0.19 & -0.09 & 0.48 \\
\hline
\end{tabular}

${ }^{*}\left[\mathrm{v}_{\mathrm{c}}\right]=\mathrm{m} / \mathrm{min},[\mathrm{f}]=\mathrm{mm} / \mathrm{rev} .,\left[\mathrm{a}_{\mathrm{p}}\right]=\mathrm{mm}$.

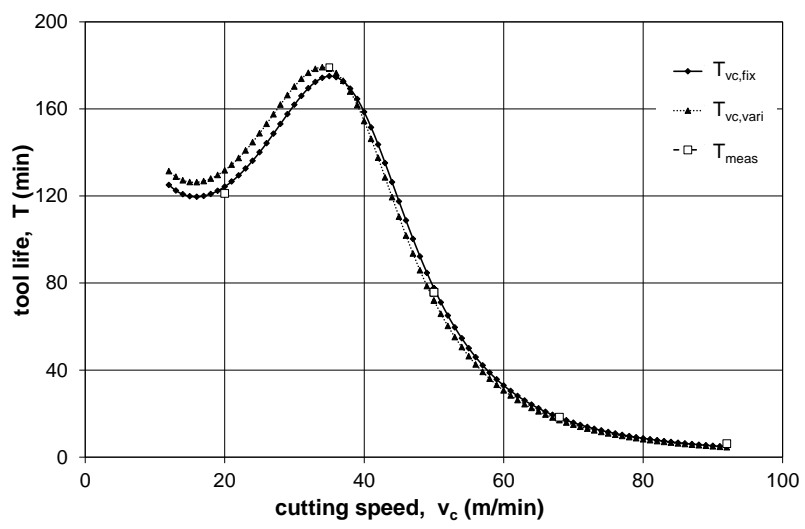

Figure 3

$T-\mathrm{v}_{\mathrm{c}}$ curves defined by fixed speed $\left(\mathrm{T}_{\mathrm{vc}, \text { fix }}\right)$, changing speed $\left(\mathrm{T}_{\mathrm{vc}, \mathrm{vari}}\right)$ and measured $\left(\mathrm{T}_{\text {meas }}\right)$ values 
As Table 3 shows, the model experiment series consist of 3 variations each. The first part of the series covers the range of cutting speed where there is the maximum of $\mathrm{v}_{\mathrm{c}}-\mathrm{T}$ curve, at cutting speed $v_{c 23}$.

Table 2

Technological parameters for fixed and periodically changing turning

\begin{tabular}{|c|c|c|c|c|c|c|}
\hline Designation & Symbol & $\mathrm{i}=1$ & $i=2$ & $i=3$ & $\mathrm{i}=4$ & $i=5$ \\
\hline Number of revolutions & $\mathrm{n}_{\text {spindle }}[1 / \mathrm{min}]$ & 142 & 250 & 354 & 480 & 650 \\
\hline Cutting speed & $\begin{array}{ll}\mathrm{v}_{\mathrm{c}, \mathrm{i}} & {[\mathrm{m} / \mathrm{min}]}\end{array}$ & 20.06 & 35.33 & 50.02 & 67.82 & 91.85 \\
\hline Operation time & {$[\mathrm{min}]$} & 2.8169 & 1.6000 & 1.299 & 0.8333 & 0.6154 \\
\hline Piece number & $\mathrm{N}_{\mathrm{p}, \mathrm{i}} \quad$ [piece] & 43 & 112 & 67 & 22 & 10 \\
\hline \multirow{2}{*}{ Tool life } & $\mathrm{T}_{\mathrm{vc}, \mathrm{fix}}[\mathrm{min}]$ & 121.1 & 179.2 & 75.7 & 18.3 & 6.15 \\
\hline & $\mathrm{T}_{\mathrm{vc}, \text { vari }}[\mathrm{min}]$ & 131.2 & 178 & 71.8 & 17.2 & 4.6 \\
\hline
\end{tabular}

Table 3

Number of bore holes turned with two speeds each until the wear off of the cutting edge

\begin{tabular}{|c|c|c|c|c|c|c|c|c|c|c|c|c|c|}
\hline \multirow{2}{*}{ 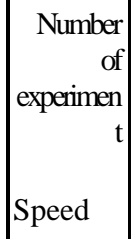 } & \multicolumn{2}{|c|}{1} & \multicolumn{2}{|c|}{2} & \multicolumn{2}{|c|}{3} & \multicolumn{2}{|c|}{4} & \multicolumn{2}{|c|}{5} & \multicolumn{2}{|c|}{6} & \multirow{2}{*}{$\begin{array}{c}\Sigma \Delta \mathrm{t}_{\mathrm{i}} / \mathrm{T} \\
\mathrm{i}\end{array}$} \\
\hline & $\begin{array}{c}\mathrm{N}_{\mathrm{p}, 1} \\
\text { [piece } \\
\text { ] }\end{array}$ & $\begin{array}{c}\Delta \mathrm{t}_{1} \\
\mathrm{~min} \\
]\end{array}$ & $\begin{array}{c}\mathrm{N}_{\mathrm{p}, 2} \\
\text { [piece } \\
\text { ] }\end{array}$ & $\begin{array}{c}\Delta \mathrm{t}_{2} \\
{[\mathrm{~min}} \\
]\end{array}$ & $\begin{array}{c}\mathrm{N}_{\mathrm{p}, 3} \\
\text { [piece } \\
\text { ] }\end{array}$ & {$\left[\begin{array}{c:}\Delta \mathrm{t}_{3} \\
{[\mathrm{~min}}\end{array}\right]$} & $\begin{array}{c}\mathrm{N}_{\mathrm{p}, 4} \\
\text { piece } \\
\text { ] }\end{array}$ & $\begin{array}{c}\Delta \mathrm{t}_{4} \\
{[\mathrm{~min}} \\
]\end{array}$ & $\begin{array}{c}\mathrm{N}_{\mathrm{p}, 5} \\
\text { [piece } \\
\text { ] }\end{array}$ & $\begin{array}{c}\Delta \mathrm{t}_{5} \\
{[\mathrm{~min}} \\
]\end{array}$ & $\begin{array}{c}\mathrm{N}_{\mathrm{p}, 6} \\
\text { [piece } \\
\text { ] }\end{array}$ & $\begin{array}{c}\Delta \mathrm{t}_{6} \\
{[\mathrm{~min}} \\
]\end{array}$ & \\
\hline$v_{\mathrm{cl} 1}$ and $v_{\mathrm{c} 3}$ & 24 & $\begin{array}{c}67.6 \\
1\end{array}$ & - & - & 31 & $\begin{array}{c}35.0 \\
3\end{array}$ & - & - & - & - & - & - & 1.021 \\
\hline $\mathrm{v}_{\mathrm{cl} 1}$ and $\mathrm{v}_{\mathrm{c} 2}$ & 30 & $\begin{array}{c}84.5 \\
1\end{array}$ & 40 & 64 & - & - & - & - & - & - & - & - & 1.055 \\
\hline$v_{\mathrm{c} 2}$ and $v_{\mathrm{c} 3}$ & - & - & 36 & 57.6 & 43 & $\begin{array}{c}48.5 \\
9\end{array}$ & - & - & - & - & - & - & 0.963 \\
\hline$v_{\mathrm{c} 3}$ and $v_{c 4}$ & - & - & - & - & - & - & 28 & $\begin{array}{c}31.6 \\
4\end{array}$ & 11 & 9.17 & - & - & 0.918 \\
\hline $\mathrm{v}_{\mathrm{c} 3}$ and $\mathrm{v}_{\mathrm{c} 5}$ & - & - & - & - & - & - & 40 & $\begin{array}{c}45.2 \\
0\end{array}$ & - & - & 5 & 3.08 & 1.097 \\
\hline $\mathrm{v}_{\mathrm{c} 4}$ and $\mathrm{v}_{\mathrm{c} 5}$ & - & - & - & - & - & - & - & - & 15 & 12.5 & 3 & 1.85 & 0.982 \\
\hline
\end{tabular}

By means of Equation (15), in any part of the series 3 equations can be set up from which the constants $C_{T 1}, C_{T 2}$, and $C_{T 3}$ can be calculated. Table 4 summarises the constants defined from the results of the first part of the series.

The last column of Table 3 also contains the sums calculated by Equation (12), whose dispersion is indicated in Figure 4 on a so-called Gauss paper. Here on the vertical axis (ordinate) the scale was made on the basis of the error function; $\mathrm{P}_{\mathrm{i}}$, however, is the estimation of the error function calculated from the results 
obtained by the formula given in Figure 4. The dispersion of the data $\Sigma \Delta \mathrm{t}_{\mathrm{i}} / \Delta \mathrm{T}_{\mathrm{i}}$ is typical in cutting examinations; their average, however, closely approaches the value 1 given in Equation (9).

By means of the constants summarised in Table 4, the values can be calculated of $T_{v c, v a r i}$ in the $\mathrm{v}_{\mathrm{c}}-\mathrm{T}$ curve which can be defined by turning at periodically changing speeds. The bottom line of Table 2 contains this data, while the close relationship of values $T_{v c, f i x}$ and $T_{v c, v a r i}$ is presented in Figure 5.

The number of the parts produced with the tool edge until reaching the allowed value of wear (e.g. VB) can also be calculated from the data above. For the variations indicated in Table 3, the number of the parts is shown in Figure 6.

Table 4

Constants of function (2) at speeds changing periodically ${ }^{*}$

\begin{tabular}{|c|c|}
\hline Constant $\mathrm{C}_{\mathrm{Ti}}$ & Value \\
\hline $\mathrm{C}_{\mathrm{T} 1}$ & 1334540 \\
\hline $\mathrm{C}_{\mathrm{T} 2}$ & -74.51304 \\
\hline $\mathrm{C}_{\mathrm{T} 3}$ & 1596.56 \\
\hline
\end{tabular}

Calculated from $\mathrm{v}_{\mathrm{c} 1}-\mathrm{v}_{\mathrm{c} 3}$ data

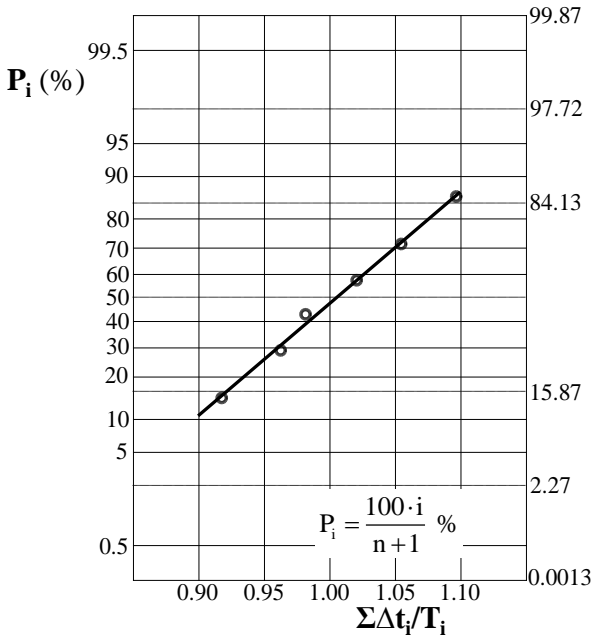

Figure 4

Dispersion of $\Sigma \Delta \mathrm{t}_{\mathrm{i}} / \mathrm{T}_{\mathrm{i}}$ values 


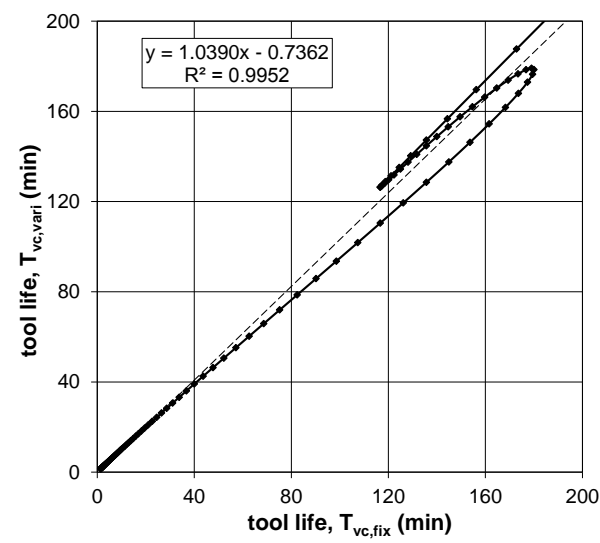

Figure 5

The relationship of tool lives stated by $T_{v c, f i x}$ fixed speed and $T_{v c, v a r i}$ changing speed cutting

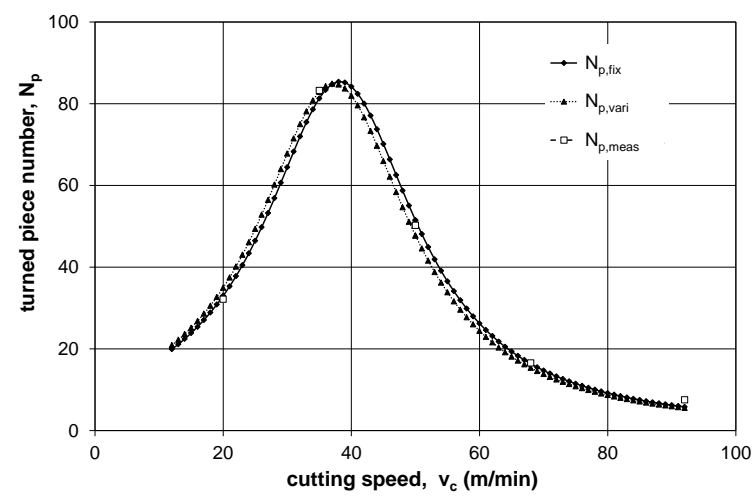

Figure 6

Number of parts as a function of cutting speed

\section{Applications}

The applicability of the general tool life function extended to the cutting with changing or alternate speed can be illustrated well in the examples of face turning and taper turning and also by the economic examination of tool performance.

\subsection{Turning of Conical Surfaces}

In the machining of internal cylindrical surfaces it has been found that constants $C_{T i}$ also depend on diameter of the workpiece $D_{w}$ besides feed $f$ and depth of cut $a_{p}$ [12]. In these cases Equation (12) takes the form of 
$\sum_{i=1}^{N} \Delta t_{i} \cdot \frac{v_{c}^{3}+C_{T 2 i} \cdot v_{c}^{2}+C_{T 3 i} v_{c}}{C_{T 1 i}} \cong 1$

with continuously changing cutting speed; however, in face turning or taper turning, for example, it takes the form of

$\int_{0}^{t_{p}} \frac{v_{c}^{3}+C_{T 2} \cdot v_{c}^{2}+C_{T 3} \cdot v_{c}}{C_{T 1}} d t \cong 1$

In the frequent case when $N_{p}$ parts are produced in sequence until the edge is worn off, on the right side of Equations (21) and (22) there is $1 / \mathrm{N}_{\mathrm{p}}$ instead of 1.

For an example of the continuous change of cutting speed, the task is the hard turning of an internal cylindrical surface with a 1:5 taper made of $100 \mathrm{Cr} 6$ (HRC60 \pm 2 ) hardened steel. In this example the length of the cone is $\ell=40 \mathrm{~mm}$, the tool geometry, the feed $f$ and depth of cut $a_{p}$ are the same, however, diameter $D$ changes:

$$
D(t)=D_{0}-\frac{n \cdot f}{5} t
$$

Therefore here the values $v_{c 12}, v_{c 23}$ and $T_{23}$ defining $C_{T i}$ constants also depend on time. Putting technological data into Equations (3)-(5) we obtain

$v_{c_{12}}=7.7007 \cdot D^{0.19}$

$v_{c_{23}}=24.1192 \cdot D^{0.16}$

$T_{23}=101.6348 \cdot D^{0.48}$

with which the constants $C_{T 1}, C_{T 2}, C_{T 3}$ can be calculated. The number of parts $N_{p}$ that can be produced until the tool edge has been worn off can be simply calculated with a numerical method by means of Equation (23)

$\int_{0}^{t_{p}} \frac{v_{c}^{3}+C_{T 2} \cdot v_{c}^{2}+C_{T 3} \cdot v_{c}}{C_{T 1}} d t \cong \frac{1}{N_{p}}$

The cutting time before the tool wears off

$T_{\text {cut }}=N_{p} \times t_{p}$,

where $t_{p}=\ell /(f \times n)$. The results of the calculation are shown in Figure 7. As can be seen, the character of the $\mathrm{v}_{\mathrm{c}}-\mathrm{T}_{\text {cut }}$ function can be compared with tool life $T$ according to Figure 3; however, because of the continuous change of speed in taper turning, the locations of the extreme values are somewhat modified: they are shifted towards the higher values, however, their maximums are almost the same. 


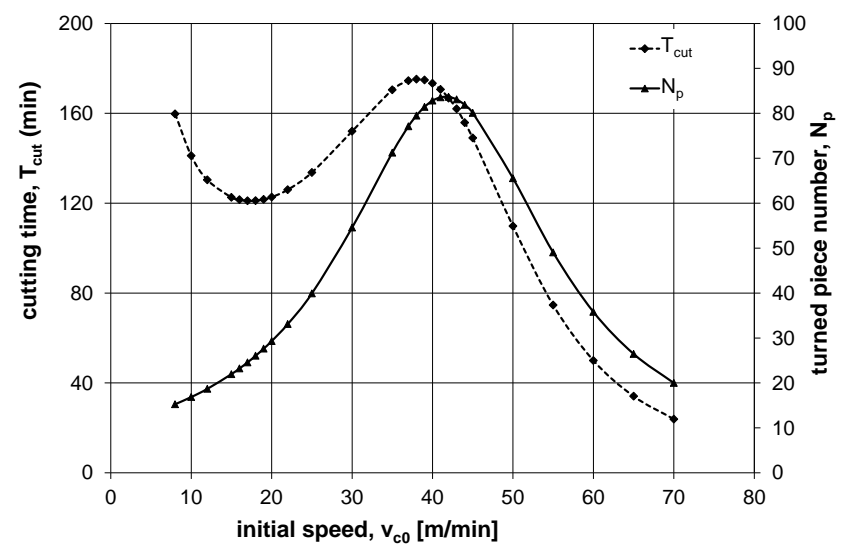

Figure 7

Number of parts and cutting time machined by taper turning until the wear off of the edge

\subsection{Economics of Cutting}

Several points of view have to be considered in economic examinations of cutting; however, in the present case the aim the economic analysis is to explore how the tool life influences the economy and productivity. So at first approach, the other cost factors of production beyond the technological parameters and the related different technological limits can be ignored.

Productivity can be characterised in the simplest way by the material volume cut during a time unit, that is, it can be calculated by

$Q=\frac{a_{p} \cdot f \cdot v_{c}}{t_{c h}+T} \cdot T\left(\mathrm{~cm}^{3} / \mathrm{min}\right)$

where $t_{c h}$ is the time needed to change the tool.

To define the cutting speed economically from the point of view of tool life, it is expedient to calculate the cost of cutting of the material quantity by unit of volume:

$$
K=\frac{1}{a_{p} \cdot f \cdot v_{c}}\left[k_{m}+\frac{t_{c h} \cdot k_{m}+K_{\text {tool }}}{T}\right]\left(€ / \mathrm{cm}^{3}\right),
$$

and here $k_{m}$ is the so-called minute cost of the machine tool, however $K_{\text {tool }}$ is the cost of one edge of the tool.

As is known, these specific economic indexes have extreme values depending on the cutting speed, the position of which can simply be expressed with formulas; in the case of the Taylor formula, by calculating the tool life that is optimal from the point of view of productivity and economy. In the case of the general $\mathrm{v}_{\mathrm{c}}-\mathrm{T}$ tool life 
function the calculation of this optimal tool life would need the solution of a cubic equation originating from Equations (2) and (17), which can be handled by the Cardano method - a program can be created for it, but that would be rather labor intensive. However, by means of a direct numerical method, e.g. an ordinary spreadsheet program, all the necessary information on productivity and economy can be gained.

Functions (27) and (28) can be seen in Figure 8 with the experimental data of turning discussed in Section 4, where the time of the tool change is $t_{c h}=5 \mathrm{~min}$, the cost of the edge is $K_{\text {tool }}=4 €$, the minute cost of the machine tool is $\mathrm{k}_{\mathrm{m}}=0.25 € / \mathrm{min}$ and $\mathrm{a}_{\mathrm{p}} \times \mathrm{f}=0.0075 \mathrm{~mm}^{2}$. So that the characteristic curve of $\mathbf{v}_{\mathbf{c}}$ cutting speed and $K$ specific cost of cutting as well as $Q$ productivity can be illustrated in a diagram: Figure 8 shows a 20 -fold $K$ specific cost and a 120 -fold $Q$ specific chip output.

Here tool life $T$ is an independent variable of the calculation; in reality, however, the aim is to define the cutting speed that is optimal from the point of view of productivity or expenditure. The characteristic curve of economic indices can be evaluated on the basis of Figure 8, then from the related spreadsheet table the $v_{c}$, opt value, which is in Table 5, can be read with optional accuracy. It can be seen that the specific economic characteristics defined for turning with fixed speed and for turning with periodically changing speed are almost the same.

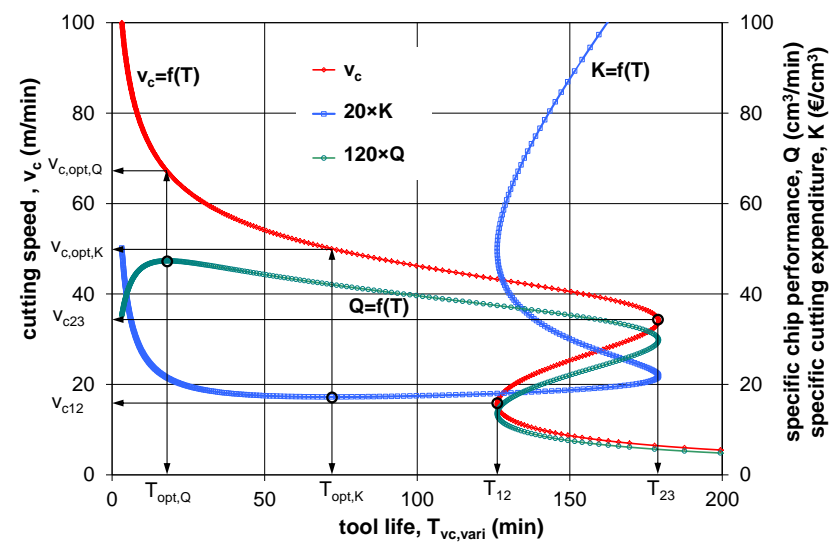

Figure 8

Specific cutting expenditure $\left(\mathrm{K}, € / \mathrm{cm}^{3}\right)$ and chip performance $\left(\mathrm{Q}, \mathrm{cm}^{3} / \mathrm{min}\right)$ in hard boring

It follows from Equation (28) that the increase of tool expenditure $K_{\text {tool }}$ increases the tool life optimal for economy. In an extreme case it may occur that $T_{o p t, K}$ slides in between the borders of $T_{12}-T_{23}$, where - as can be seen in the $T-v_{c}$ curve - up to three values offer themselves for the speed and consequently for machining cost $K$. Obviously, the most economically beneficial one is to be chosen from them if the other circumstances make that possible. When the application of optimal cutting speed defined in that way encounters some barriers, it can easily be decided what technology may closest approach the optimum. 
Table 5

Comparison of specific characteristics of cutting in continuous cutting and cutting with changing speed

\begin{tabular}{|l|c|c|c|c|c|c|}
\hline Cutting method & $\begin{array}{c}\mathrm{v}_{\mathrm{c}, \text { opt, } \mathrm{Q}} \\
{[\mathrm{m} / \mathrm{min}]}\end{array}$ & $\begin{array}{c}\mathrm{T}_{\text {opt } \mathrm{Q}} \\
{[\mathrm{min}]}\end{array}$ & $\begin{array}{c}\mathrm{Q}_{\text {opt }} \\
{\left[\mathrm{cm}^{3} / \mathrm{min}\right]}\end{array}$ & $\begin{array}{c}\mathrm{v}_{\text {opt } \mathrm{K}} \\
{[\mathrm{m} / \mathrm{min}]}\end{array}$ & $\begin{array}{c}\mathrm{T}_{\text {opt }, \mathrm{Q}} \\
{[\mathrm{min}]}\end{array}$ & $\begin{array}{c}\mathrm{K}_{\text {opt }} \\
{\left[€ / \mathrm{cm}^{3}\right]}\end{array}$ \\
\hline Cutting with fixed speed & 67.5 & 18.8 & 0.400 & 51.0 & 71.1 & 0.847 \\
\hline Cutting with changing speed & 67.8 & 17.3 & 0.400 & 49.3 & 76.9 & 0.881 \\
\hline
\end{tabular}

\section{Summary}

The most important point of view of cutting ability is tool life. Usually it is described by the well-known Taylor formula, which, in the basic case gives the tool life as function of the cutting speed, but this is only valid for a monotonously decreasing $\mathrm{T}-\mathrm{v}_{\mathrm{c}}$ curve. To describe a $\mathrm{T}-\mathrm{v}_{\mathrm{c}}$ curve having extreme values as well, we introduced a general tool life function proved by cutting experiments. A frequent problem is, however, that cutting goes on sequentially with the same tool at several different speeds, and then this formula can be used only with difficulty. With periodically changing cutting speed the equation $\Sigma \Delta t_{i} / T_{i} \cong 1$ is valid theoretically and experiments have proven this. From this a general form of $\mathrm{T}-\mathrm{v}_{\mathrm{c}}$ curve can be deduced which can also be used with cutting at periodically changing cutting speeds. In the case of cutting at different speeds, an equivalent speed and the related tool life can be defined which can already been handled by the general Kundrák tool-life function. By the calculation of the equivalent speed it is possible to define the $T-v_{c}$ curve under manufacturing conditions, even in cutting with changing speed, and the general tool life function can be defined by operational measurements. The applicability of this function is demonstrated by examples of taper turning and cutting optimisation.

\section{Acknowledgements}

This research was (partially) carried out in the framework of the Centre of Excellence of Innovative Engineering Design and Technologies at the University of Miskolc. The work was presented with the support of the Hungarian Scientific Research Fund (Number of Agreement: OTKA K 78482), which the authors greatly appreciate.

\section{References}

[1] ISO Standard 3685 Tool-Life testing with Single-Point Turning Tools

[2] El Baradie M. A.: The Effect of Varying the Workpiece Diameter on the Cutting Tool Clearance Angle in Tool-Life Testing. Wear 195 (1996) pp. 201-205

[3] Arsecularatne J. A., Zhang L. C., Montross C., Mathew P.: On Machining of Hardened AISI D2 Steel with PCBN Tools, Journal of Material Processing Technology 171 (2006) pp. 244-252 
[4] Arsecularatne J. A., Zhang L. C., Montross C.: Wear and Tool Life of Tungsten Carbide, PCBN and PCD Cutting Tools, International Journal of Machine Tools and Manufacture 46 (2006) pp. 482-491

[5] Sahin Y.: Comparison of Tool Life between Ceramic and Cubic Boron Nitride (CBN) Cutting Tools when Machining Hardened Steel, Journal of Material Processing Technology 209 (2009) pp. 3478-3489

[6] Chinchanikar S., Choudhury S. K.: Investigations on Machinability Aspect of Hardened AISI 4340 Steel Different Levels of Hardness Using Coated Carbide Tools, Int. Journal of Refractory Metals and Hard Materials 38 (2013) pp. 124-133

[7] Fekete G., Horváth S., Czifra Á.: Microgeometry Tests of 'Contradictory' Surfaces with Various Evaluation Techniques, Acta Polytechnica Hungarica, Vol. 4, No. 2, 2007, pp. 87-97

[8] Mikó B., Beňo J., Maňková I.: Experimental Verification of Cups Heights when 3D Milling Rounded Surfaces, Acta Polytechnica Hungarica, Vol. 9, No. 6, 2012, pp. 101-116

[9] Khan S. A., Soo S. L., Aspinwall D. K., Sage C., Harden P., Fleming M., White A., M'Saoubi R.: Tool Wear/Life Evaluation when Finish Turning Inconel 718 Using PCBN Tooling, 5 ${ }^{\text {th }}$ CIRP Conference on High Performance Cutting, Procedia CIRP Vol. 1, 2012, pp. 283-288

[10] Aykut S., Kentli A., Gülmez S., Yazıcıoğlu O.: Robust Multiobjective Optimization of Cutting Parameters in Face Milling, Acta Polytechnica Hungarica, Vol. 9, No. 4, 2012, pp. 85-100

[11] Salvatore F., Saad S., Hamdi H.: Modelling and Simulation of Tool Wear During the Cutting Process, $14^{\text {th }}$ CIRP Conference on Modelling of Machining Operations (CIRP CMMO) Procedia CIRP 8 (2013) 305-310

[12] Kundrák J.: The Scientific Principles of Increasing the Effectiveness of Inner Surfaces Cutting with CBN Tools, Kharkov, 1996, p. 368

[13] Pluta Z., Hrynieviez T.: Advanced Model of the Tool Edge Blunting under Machining, Int. J. Manuf. Technol. 51 (2010) pp. 35-43

[14] Mamalis A. G., Kundrák J., Horváth M.: Wear and Tool Life of CBN Cutting Tools, Int. J. Adv. Manuf. Technol. 20 (2002) pp. 475-479

[15] Kundrák J., Pálmai Z.: Investigation of Machinability in Boring of Inner Cylindrical Surfaces of Hardened Bearing Steels, Proc. ICT-2012, $13^{\text {th }}$ International Conference on Tools, 2012 Miskolc, Hungary, pp. 165-170

[16] Pálmai Z.: Anwendung der Taylorschen Gleichung auf die Zerspanung mit wechselnd sich Änderungen Schnittgeschwindigkeiten. Archiv für das Eisenhüttenwesen 49 Nr. 2 (1979) pp. 89-93 
[17] Zorev N. N., Granovskij G. I., Loladze T. N., Tretyakov I. P.: Razvitie nauki o rezanii metallov, Mashinostroenije, Moscow, 1967, p. 413

[18] Olovsjö S., Nyborg L.: Influence of Microstructure on Wear Behaviour of Uncoated WC Tools in Turning of Alloy 718 and Waspaloy, Wear 282-283 (2012) pp. 12-21

[19] Pálmai Z.: Standzeit des Werkzeuges beim Plandrehen. Archiv für das Eisenhüttenwesen 49 Nr. 10 (1984) pp. 499-502 